\title{
PATER ET FILIUS: BREVES NOTAS SOBRE EL FORO TERRITORIAL COMPETENTE EN LAS DENOMINADAS ACTIONES ADIECTICIAE QUALITATIS
}

\author{
$M^{a}$ LUISA LÓPEZ HUGUET
}

Becaria F.P.I. Universidad de La Rioja. Área de Derecho civil Universidad de La Rioja

SUMARIO

I. INTRODUCCIÓN: FUNDAMENTO, ORIGEN Y TIPOLOGÍA DE LAS ACTIONES ADIECTICIAE QUALITATIS. II. EL FORO TERRITORIAL COMPETENTE EN LAS ACTIONES ADIECTICIAE QUALITATIS FRENTE A LOS NEGOCIOS REALIZADOS POR EL FILIUS FAMILIAS: PLANTEAMIENTO DEL PROBLEMA. II.1. Legitimación procesal pasiva del filius familias. II.2. Independencia domiciliaria del filius familias. III. EL FORO TERRITORIAL COMPENTENTE EN LAS ACTIONES ADIECTICIAE QUALITATIS FRENTE A LOS NEGOCIOS CELEBRADOS POR EL FILIUS FAMILIAS: UNA PROPUESTA DE SOLUCIÓN. IV. CONCLUSIÓN.

\section{RESUMEN}

Las $a$. a. q. eran acciones con transposición de personas mediante la cual la condemnatio recaía sobre una persona distinta a la nombrada en la intentio. Ello planteaba el problema de determinar cuál era el foro territorial cuando los dos sujetos eran titulares de un domicilio diferente. La solución reside en concretar qué obligatio se pretendía sancionar con estas acciones: aquélla de la persona inicialmente demanda (p.e. filius familias) o aquélla de la persona finalmente condenada (p.e. pater familias). 


\section{INTRODUCCIÓN: FUNDAMENTO, ORIGEN Y TIPOLOGÍA DE LAS ACTIONES ADIECTICIAE QUALITATIS.}

En palabras de Martín Minguijón, las actiones adiecticiae qualitatis, fueron "un recurso pretorio por el cual quedaba alterado el principio de que tanto la absolución como la condena debía recaer necesariamente en la persona designada en la intentio" ${ }^{1}$.

Con ellas el pretor vino a corregir la indefensión en que se encontraban los terceros que negociaban con personas subiecti cuya incapacidad patrimonial, que no negocial, comportaba su falta de responsabilidad por los contratos que celebraban, responsabilidad que tampoco podía hacerse recaer sobre el pater familias, en la medida que si bien éste era acreedor de todo lo adquirido por la persona sometida a su patria potestas $^{2}$, sin embargo, su posición no podía verse perjudicada por los actos que efectuaran sus sometidos ni incluso cuando les hubiera dado la orden de celebrarlos, tal y como nos indica Gayo con relación a los esclavos: melior condicio nostra per servos fieri potes, deterior fieri non potest ${ }^{3}$.

\footnotetext{
${ }^{1}$ A.R. MARTÍN MINGUIJÓN, Acciones ficticias y acciones adyecticias. Fórmulas, Madrid, 2001, pp. 151. La denominación de estas acciones proviene de la época de los glosadores que la toman de un pasaje de Paulo ( D. XIV, I, $5 \S 1$ ). Sobre las mismas vid., con carácter general, S. SOLAZZI, "<<Condictio $>>$ e azioni adiettizie", en Scritti di Diritto romano, I (1899-1913), Napoli, 1955, pp. 269 ss; E. VALIÑO, "Las <<actiones adiecticiae qualitatis $>>$ y sus relaciones básicas en el Derecho romano", en Anuario de Historia del Derecho Español, 37, 1967, pp. 339 ss; idem, "Las relaciones básicas de las acciones adyecticias", en Anuario de Historia del Derecho Español, 38, 1968, pp. 377 ss; A. GUARINO, su voz <<actiones adiecticiae qualitatis $>>$, en Novissimo Digesto Italiano, I.1, Torino, 1957, pp. 270 ss; C. FADDA, Istituti commerciali del Diritto romano. Introduzione, Napoli-Paris, 1987, pp. 50 ss; J.L. MURGA, Derecho romano clásico. II. El proceso, Zaragoza, 1989, pp. 73 ss; idem, "El sc. Macedoniano y las <<actiones adiecticiae qualitatis $>>$ ", en Actas del Segundo Congreso Iberoamericano de Derecho Romano, Murcia, 1988, pp. 259 ss; G. PROVERA, Lezioni sul processo civile giustinianeo, I-II, Torino, 1989, pp. 259 ss; J. HERNANZ PILAR, El ivssvm en las relaciones potestativas, Valladolid, 1993, pp. 87 ss; A. WACKE, "Alle origini della rappresentanza diretta: Le azioni adiettizie", en Estudios de Derecho romano y moderno en cuatro idiomas, Madrid, 1996, pp. 237 ss; A. D'ORS, Derecho privado romano, Pamplona, 1997, pp. 303 ss; M.J. GARCÍA GARRIDO, Derecho privado romano. Casos, acciones, instituciones, Madrid, 2000, pp. 300-301; B. PERIÑÁN GÓMEZ, Antecedentes y consecuencias del SC. Macedoniano, Valencia, 2000, pp. 113 ss; M. MICELI, Sulla struttura formulare delle 'actiones adiecticiae qualitatis', Torino, 2001.

${ }^{2}$ El principio de que toda adquisición efectuada por un subiecti revertía al patrimonio del pater o dominus deriva de aquel otro qui in potestae alterius est, suum habere potest, ambos dos recogidos por Gayo, Institutae, II, 87 (= D. XLI, I, 1O, § 1). Sobre la primitiva incapacidad patrimonial del filius familia que será paulatinamente mitigada a través de los peculios, entre otros, F. LA ROSA, I peculi speciali in Diritto romano, Milano, 1953, pp. 5 ss; M. GARCÍA GARRIDO, Ivs Vxorivm. El régimen patrimonial de la mujer casada en el Derecho español, Madrid, 1958, pp. 5 ss; A. BURDESE, su voz $<<$ capacità (Diritto romano) $>>$, en Enciclopedia del Diritto, VI, Milano, 1960, pp. 1-3; B. ALBANESE, Le persone nel Diritto romano privato romano, Palermo, 1979, pp. 211-213, 246-247 y 271 ss; A. FERNÁNDEZ DE BUJÁN, El "filiusfamilias" independiente en Roma y en el Derecho español, Madrid, 1981, pp. 25 ss; PROVERA, Lezioni sul processo civile giustinianeo, cit., pp. 260 ss; A. D'ORS, Elementos de Derecho privado romano, Pamplona, 1992, pp. 52 ss; M.C. FAYER, La familia romana. Aspetti giuridici ed antiquari, Parte prima, Roma, 1994, pp. 250 ss; WACKE, "Le pécule: patrimoine du père ou propiété du fils? Le destin du pécule après la fin de la puissance domestique", en Estudios de Derecho romano y moderno en cuatro idiomas, cit., pp. 163.

${ }^{3}$ D. L, XVII, 133 (Gaius libro VIII. ad Edictum provinciale); D. XLVI, IV, 8 §. LA ROSA, I peculi speciali in Diritto romano, cit., pp. 6; VALIÑO, "Las $<<$ actiones adiecticiae qualitatis $>>$ y sus relaciones básicas en Derecho romano", cit., pp. 339-340; FERNÁNDEZ DE BUJÁN, E1 "filiusfamilias" independiente en Roma y en el Derecho español, cit., pp. 25 ss; PROVERA, Lezioni sul processo civile giustinianeo, cit., pp. 263 ss; D'ORS, Elementos de Derecho privado romano, cit., pp.
} 
Para mitigar estas situaciones injustas en las que los subiecti intervenían como agentes en las relaciones económicas de su pater o dominus, en opinión de Hernanz Pilar, el pretor "arbitró en su edicto impulsado por razones de equidad, en interés del creciente tráfico comercial que surgió después de las guerras púnicas, del tercero contratante e incluso del propio cabeza de familia", este sistema de acciones a través de las cuales "los negocios generadores de obligaciones efectuados por los subiecti revertían, o proyectaban su eficacia, también en la esfera patrimonial dominical, haciéndo al pater responsable de las consecuencias onerosas que conllevaban tales débitos"4.

El medio técnico adoptado a tal fin fue, como señala Periñán Gómez, la transposición de personas en sus correspondientes fórmulas, de tal forma que en la intentio figuraba el subiectus como demandado y en la condemnatio figuraba el pater familias, permitiendo así que la sentencia, absolutoria o de condena, recayera sobre una persona distinta a la inicialmente demanda ${ }^{5}$.

Tradicionalmente dentro de este sistema de acciones se han encuadrado la actio quod iussu, institoria, exercitoria, tributoria, de peculio y de in rem verso ${ }^{6}$. No obstante, tras el estudio de Valiño, no faltan autores que comparten su opinión de excluir la actio tributoria, ejercitable en el caso de una distribución dolosamente hecha por el pater familias o dominus en el reparto del peculio ${ }^{7}$.

53; WACKE, "Alle origini della rappresentaza diretta: Le azioni adiettizie", cit., pp. 238; PERIÑÁN GÓMEZ, Antecendentes y consecuencias del SC. Macediniano, cit., pp. 97.

${ }^{4}$ HERNANZ PILAR, El ivssvm en las relaciones potestativas, cit., pp. 87. Las razones de equidad en la creación de estas acciones han sido también apuntandas por PROVERA, Lezioni sul processo civile giustinianeo, cit., pp. 263; MARTÍN MINGUIJÓN, Acciones ficticias y acciones adyecticias. Fórmulas, cit., pp. 153.

5 PERIÑÁN GÓMEZ, Antecedentes y consecuencias del SC. Macedoniano, cit., pp. 114; GUARINO, su voz <<actionis adiecticiae qualitatis $>>$, cit., pp. 271; VALIÑO, "Las <<actiones adiecticiae qualitatis $>>$ y sus relaciones básicas en Derecho romano", cit.,pp. 349 ss; C.A. CANNATA, Profilo instituzionale del processo privato romano, II: Il processo formulare, Torino, 1982, pp. 131; MURGA, Derecho romano clásico, II. El proceso, cit., pp. 73; PROVERA, Lezioni sul processo civile giustinianeo, cit., pp. 265; WACKE, "Alle origini della rappresentanza diretta: Le azioni adiettizie", cit., pp. 239; A. FERNÁNDEZ BARREIRO-J. PARICIO, Fundamentos de Derecho patrimonial romano, Madrid, 1997, pp. 178-179; D'ORS, Derecho privado romano, cit., pp. 303; HERNANZ PILAR, El ivssvm en las relaciones potestativas, cit., pp. 87 n. 2; GARCÍA GARRIDO, Derecho privado romano, cit., pp. 300; MARTÍN MINGUIJÓN, Aciones ficticias y acciones adyecticias. Fórmulas, cit., pp.149 ss. Cfr. MICELI, Sulla struttura formulare delle 'Actiones adiecticiae qualitatis', cit., pp. 37 ss y 89 ss.

${ }^{6}$ En este sentido, entre otros, GUARINO, su voz $<<$ actionis adiecticiae qualitatis $>>$, cit., pp. 271 ss; FADDA, Istituti commerciali del Diritto romano. Introduzione, cit., pp. 50 ss; GARCÍA GARRIDO, Ivs Vxorivm. El régimen patrimonial de la mujer casada en derecho romano, cit., pp. 15; MURGA, Derecho romano clásico, II. El proceso, cit., pp. 74; HERNANZ PILAR, El ivssvm en la relaciones potestativas, cit., pp. 87 n. 2; MICELLI, Sulla struttura formulare delle 'Actiones adiecticiae qualitatis', cit., pp. 320 ss.

7 E. VALIÑO, "La <<actio tributoria>>, en Studia et Documenta Historiae et Iuris, 33, 1967, pp. $103 \mathrm{ss}$, considera que las acciones adyecticias se añaden a una relación preexistente, cuya acción ha de tener un oportere en su fórmula procesal y que la actio tributoria carece de este presupuesto dado que con ella solo se pide lo que se ha dejado dolosamente de distrubuir por lo que no se trata de la antigua obligación del subiecti sino de una obligación nueva. En este sentido, entre otros, FERNÁNDEZ BARREIRO- PARICIO, Fundamentios de Derecho patrimonial romano, cit., pp. 178-179: "No tiene, en cambio, el carácter de adyecticia, aunque a veces se incluya entre esas acciones, la actio tributoria. Cuando el peculio consiste en mercancías, los acreedores pueden pedir que se efectúa el reparto del peculio en proporción a sus respectivos créditos, incluyendo los créditos naturales que el mismo padre tuviera contrasu hijo. Si el pater familias realiza un reparto doloso, los acreedores pueden ejercitar 
Por otro lado aunque determinados autores como $\mathrm{Costa}^{8}$, intentan atribuirles una mayor antigüedad, la gran parte de la doctrina considera que su origen no puede ser anterior a la lex Aebutia ${ }^{9}$. En efecto, la mayor parte de la doctrina admite que la actio exercitoria, concedida cuando el padre o dueño pusiera de patrón (praepositio) de una nave al hijo o al esclavo y alguien realice un negocio en base a la misma ${ }^{10}$, y la actio institoria, concedida cuando se contrate con un hijo o esclavo que el pater familias hubiera puesto al frente de una tienda o de cualquier otro comercio siempre que el negocio estuviera relacionado con dicho comercio ${ }^{11}$, fueron las primeras en aparecer, entre finales del siglo II y la primera mitad del siglo I a. C., y que a partir de ahí, el resto de las acciones fueron surgiendo paulatinamente para dar respuesta a las necesidades que la práctica comercial planteaba ${ }^{12}$.

contra él la actio tributoria para lograr una indemnización por el perjuicio sufrido"; MARTÍN MINGUIJÓN, Acciones ficticias y acciones adyecticas. Fórmulas, cit., pp. 154: "No es necesario recurrir a la transposición de sujetos para hacer efectiva la responsabilidad del pater familias por la deficiente distribución, sino que esto va a lograrse mediante esta acción que el pretor creó para proteger tales situaciones".

${ }^{8}$ E. COSTA, Storia del Diritto Romano Privato, Torino, 1925, pp. 456; F. DE MARTINO, Diritto e società nell'antica Roma, Roma, 1982, pp. 159.

${ }^{9}$ VALIÑO, "Las << actiones adiecticae qualitatis $>>$ y sus relaciones básicas en Dercho romano", cit., pp. 344 ss; HERNANZ PILAR, El ivssvm en las relaciones potestativas, cit., pp. 87 n. 2; MARTÍN MINGUIJÓN, Acciones ficticias y acciones adyecticias. Fórmulas, cit., pp. 164; MICELI, Sulla struttura formulare delle 'Actiones adiecticiae qualitatias', cit., pp. 29.

${ }^{10}$ Sobre esta acción, GUARINO, su voz $<<$ actiones adiecticiae qualitatis $>>$, cit., pp. 271; F. DE MARTINO, su voz <<exercitor $>>$, en Novissimo Digesto Italiano, VI, Torino, 1957, pp. 1088 ss; idem, "Studii sull'<<actio exercitoria>>", en Rivista del Diritto della Navegazione, VII, 1-2, 1941, pp. 7 ss (= Diritto, economia e società nel mondo romano, I, Diritto privato, Napoli-Paris, 1998, pp. $495 \mathrm{ss})$; idem, "Ancora sull'<<actio exercitoria >>", en Labeo, 4, 1958, pp. 274 ss (=Diritto, economica e società nel mondo romano, $I$, cit., pp. $629 \mathrm{ss}$ ); VALIÑO, "Las $<<$ actiones adiecticiae qualitatis $>>$ y sus relaciones básicas en Derecho romano", cit., pp. 355 ss; G. LONGO, "<<Actio exercitoria $>>-<<$ actio institoria $>>$ - <<actio quasi institoria>>", en Studi in onore di Gaetano Scherillo, II, Milano, 1972, pp. 581 ss; MURGA, Derecho romano clásico, II. El proceso, cit., pp. 74; PROVERA, Lezioni sul processo civile giustinianeo, cit., pp. 264 ss; WACKE, "Alle origini della rappresentaza diretta: Le azioni adiettizie", cit., pp. 244 ss; PERIÑÁN GÓMEZ, Antecedentes y consecuencias de SC. Macedoniano, cit., pp. 114115; MARTÍN MINGUIJÓN, Acciones ficticias y acciones adyecticias. Fórmulas, cit., pp. 173 ss; MICELI, Sulla struttura formulare delle 'Actiones adiecticiae qualitatis', cit., pp. 188 ss.

${ }^{11}$ Pampiniano creó posteriormente la actio ad exemplum institoriae o quasi institoria para extender el principio de la responsabilidad adyecticia del dominus a supuestos en los que no existía una verdadera praepositio o en el presupuesto de que al institor sólo se le encargaran negocios aislados. Sobre estas acciones, GUARINO, su voz $<<$ actiones adiecticiae qualitatis $>>$, cit., pp. 272; CERVENCA, su voz $<<$ institore $>>$, en Novissimo Digesto Italiano, VIII, Torino, 1957, pp. 756 ss; VALIÑO, "Las $<<$ actiones adiecticiae qualitatis $>>$ y sus relaciones básicas en Derecho romano", cit., pp. 355 ss; A. BURDESE, "<<Actio ad exemplum institoriae $>>$ e categorie sociali", en Bulletino dell'Istituto de Diritto Romano, 74, 1971, pp. 61 ss; LONGO, "<<actio exercotiria $>>-<<$ actio institoria $>>-<<$ actio quasi institoria $>>$ ", cit., pp. 581 ss; MURGA, Derecho romano clásico, II. El proceso, cit., pp. 74; PROVERA, Lezioni sul processo civile giustinianeo, cit., pp. 264 ss y 280 ss; WACKE, "Alle origini della rappresentanza diretta: Le azioni adiettizie", cit., pp. 248 ss; PERIÑÁN GÓMEZ, Antecedentes y consecuencias del SC. Macedoniano, cit., pp. 115; MARTÍN MINGUIJÓN, Acciones ficticias y acciones adyecticias. Fórmulas, cit., pp. 186 ss; MICELI, Sulla struttura formulare delle 'Actiones adiecticiae qualitatis', cit., pp. 188 ss.

${ }^{12}$ La duda se plantea, sin embargo, sobre cual fue el orden de aparición de estas dos acciones así como sobre el orígen de la actio quod iussu. Al respecto, vid. MARTÍN MINGUIJÓN, Acciones ficticias y acciones adyecticias. Fórmulas, cit., pp. 164 ss, donde analiza los argumentos esgrimidos por S. SOLAZZI, "L'età dell'<<actio exercitoria>>", en Scritti di Diritto romano, IV (1938-1947), Napoli, 1963, pp. 243 ss y VALIÑO, "Las <<actiones adiecticae qualitatis $>>$ y sus relaciones básicas en 
Así, como sintetiza Guarino ${ }^{13}$, la actio quod iussum, era concedida contra el pater o dominus al acreedor que hubiese celebrado un negocio de carácter obligatorio con personas in potestate cuando el pater o dominus hubiera autorizado la realización de dicho negocio ${ }^{14}$; la actio de peculio, cuando el pater o dominus hubiese atrribuido a sus subiecti la administración de un peculio y en los límites del mismo ${ }^{15}$; y la actio in rem verso, cuando el patrimonio del pater o dominus hubiera experimentado un incremento por efecto del negocio concluido por el hijo o esclavo hasta el límite de dicho beneficio o del gasto evitado ${ }^{16}$.

\section{EL FORO TERRITORIAL COMPETENTE EN LAS ACTIONES ADIECTICIAE QUALITATIS FRENTE A LOS NEGOCIOS REALIZADOS POR EL FILIUS FAMILIAS: PLANTEAMIENTO DEL PROBLEMA.}

Según Savigny, el criterio general seguido en la época clásica para determinar el foro territorial compentente en una controversia era el lugar de origen o del domicilio del demando a elección del demandante (actor sequirtur forum rei), aunque es probable que la competencia de los magistrados provinciales se determinara sólo en función del domicilio ${ }^{17}$.

Derecho romano", cit., pp. 344 ss, a favor de la anterioridad de la actio exercitoria. Cfr. PROVERA, Lezioni sul processo civile giustinianeo, cit., pp. 279, para quien es probable que la actio quod iussu fuera la primera en aparecer.

${ }^{13}$ GUARINO, su voz $<<$ actionis adiecticiae qualitatis $>>$, cit., pp. 272. Vid, así mismo, las síntesis de MURGA, Derecho romano clásico, II. El proceso, cit., pp. 75 ss; FERNÁNDEZ BARREIROPARICIO, Fundamentos de Derecho patrimonial romano, cit., pp. 179; D'ORS, Derecho privado romano, cit., pp. 303-304; PERIÑÁN GÓMEZ, Antecedentes y consecuencias del SC. Macedoniano, cit., pp. 116 ss; GARCÍA GARRIDO, Derecho privado romano, cit., pp. 300 ss.

${ }^{14}$ Sobre esta acción, VALIÑO, "Las $<<$ actiones adiecticiae qualitatis $>>$ y sus relaciones básicas en Derecho romano", cit., pp. 407 ss; PROVERA, Lezioni sul processo civile giustinianeo, cit., pp. 264 ss; WACKE, "Alle origini della rappresentanza diretta: Le azioni adiettizie", cit., pp. 242; HERNANZ PILAR, El ivssvm en las relaciones potestativas, cit., pp. 87 ss; MARTÍN MINGUIJÓN, Acciones ficticias y acciones adyecticias. Fórmula, cit., pp. 203 ss; MICELI, Sulla struttura formulare delle 'Actiones adiecticiae qualitatis', cit., pp. 309 ss.

${ }^{15} \mathrm{Al}$ cesar la patria potestas o la domenica potestas, la actio de peculio dejaba de ser perpetua para convertirse en anual (actio de peculio annalis). Al respecto, S. SOLAZZI, $"<<$ Ius deductionis $>>\mathrm{e}$ $<<$ condemnatio cum deductione $>>$ nell'<<actio de peculio $>>$ ", en Scritti di Diritto romano, I, cit., pp. 99 ss; idem, "L'<<actio de peculio annalis $>>$ contro gli eredi", en Scritti di Diritto romano, I, cit., pp. 109 ss; idem, "Studi sull'<<Actio de peculio>>", en Scritti di Diritto romano, I, cit., pp.162 ss; idem, "Peculio e $<<$ in rem versio $>>$ nel diritto classico", en Scritti di Diritto romano, I, cit., pp. 248 ss; VALIÑO, "Las $<<$ actionis adiecticiae qualitatis $>>$ y sus relaciones básicas en Derecho romano", cit., pp. 391 ss; PROVERA, Lezioni sul processo civile giustinianeo, cit., pp. 269 ss; MARTÍN, MINGUIJÓN, Acciones ficticias y acciones adyecticias. Fórmulas, cit., pp. 211 ss; MICELI, Sulla struttura formulare delle 'Actiones adiecticiae qualitatis', cit., pp. 229 ss.

${ }^{16}$ Esta acción, en consecuencia, se convirtió en una válvula de seguridad. Sobre la misma, VALIÑO, "Las $<<$ actiones adiecticiae qualitatis $>>$ y sus relaaciones básicas en Derecho romano", cit., pp. 397 ss; PROVERA, Lezioni sul processo civile giustinianeo, cit., pp. 269 ss; MARTÍN MINGUIJÓN, Acciones ficticias y acciones adyecticias. Fórmulas, cit., pp. 211 ss; MICELI, Sulla struttura formulare delle 'Actiones adiecticiae qualitatis', cit., pp. 292 ss.

${ }^{17}$ F. DE SAVIGNY, Sistema de Derecho romano actual, trad. J. Mesías y Poley, Tomo II, Madrid, 1929, pp. 162 ss; E. CUQ, Manuel des Institutiones juridiques des romains, Paris, 1917, pp. 812; A. D'ORS, Epigrafía jurídica de la España romana, Madrid, 1953, pp. 153; G. PUGLIESE, Il processo civile romano, II, Il processo formulare, Tomo I, Milano, 1963, pp. 158; F. DE MARTINO, Storia della costituzione romana, III, Napoli, 1973, pp. 293; S. M-B, BRUGUIĖRE, "Le domicile dans les droits 
Sin embargo la aplicación de este principio suscita dudas cuando el negocio generador de la controversia hubiese sido efectuado por un filius familias o por un sui iuris posibilidad, ésta última, que según Longo acabó admitiendo la jurisprundencia respecto al ejercicio de la actio execitoria y de la actio institoria ${ }^{18}$. Los motivos de las dudas son similares en ambos supuestos y se concretan tanto en el hecho de que pudieran tener capacidad procesal pasiva como en el hecho de que pudieran ser titulares de un domicilio independiente de tal forma que en relación con las acciones analizadas, podía darse el caso de que la persona designada en la intentio tuviera un domicilio distinto a la persona designada en la codemnatio.

En el presente estudio centraremos nuestra atención en el supuesto del filius familias, sin perjuicio de que la solución adoptada pueda ser extensible a los casos en los que el magister navis o el institor fueran sui iuris.

\section{1. Legitimación procesal pasiva del filius familias.}

Frente a la rigurosa incapacidad procesal del filius familias en el procedimiento de las acciones de ley, como nos indica Solazzi, a partir del procedimiento formulario se fue reconociendo su legitimación activa y pasiva en determinados supuestos ${ }^{19}$. Respecto a la legitimación pasiva, afirma el autor, la misma era una consecuencia que no se podía evitar después de haber reconocido que el filius familias podía obligarse a sí mismo válidamente, tal y como con carácter general nos lo enuncia Gayo: Filius familias ex omnibus causis tamquem pater familias obligatur et ob id agi cum eo tamquam cum patre familias potest $t^{20}$.

antiques", en Mélanges dédiés à Gabriel Marty, Tolouse, 1978, pp. 212 ss; J. SALGADO, "Contribución al estudio del <<domicilium >> en el Derecho romano", en Revista de Derecho privado, LXIV (Enero-Diciembre 1980), pp. 506-507; J. PLESCIA, "Conflict of laws in the roman Empire", en Labeo, 38.1, 1992, pp. 47; J. IGLESIAS, Derecho romano, Barcelona, 1999, pp. 128; PASCUAL LÓPEZ, La inviolabilidad del domicilio en el Derecho español, Madrid, 2001, pp. 24-25. Cfr. D. L, XVI, 190.

18 D. XIV, I, 1 § 17. LONGO, "<<Actio exercitoria $>>-<<$ actio institoria $>>-<<$ actio quasi institoria $>>$ ", cit., pp. 581 ss; DE MARTINO, "Studii sull'<<actio exercitoria $>>$ ", cit., pp. 18; GUARINO, su voz <<actionis adiecticiae qualitatis $>>$, cit., pp. 271; VALIÑO, "Las <<actiones adiecticiae qualitatis $>>$ y sus relaciones básicas en Derecho romano", cit., pp. 343; M. KASER, Derecho romano privado, trad. J. S. Cruz Teijeiro, Reus, 1982, pp. 221 ss; E. VOLTERRA, Instituciones de Derecho privado romano, trad. J. Daza Martínez, Madrid, 1986, pp. 171 y 173; MURGA, Derecho romano clásico, II. El proceso, pp. 74 n. 64; PROVERA, Lezioni sul processo civile giustinianeo, cit., pp. 279 ss; D'ORS, Elementos de Derecho privado romano, cit., pp. 55; idem, Derecho privado romano, cit., pp. 303-304; FERNÁNDEZ BARREIRO-PARICIO, Fundamentos de Derecho patrimonial romano, cit., pp. 179; WACKE, "Alle origini della rappresentanza diretta: Le azioni adiettizie", cit., pp. 237 ss; HERNANZ PILAR, El ivssvm en las relaciones potestativas, cit., pp. 93; PERIÑÁN GÖMEZ, Antecedentes y consecuencias del SC. Macedoniano, cit., pp. 115 n. 87; MARTÍN MINGUIJÓN, Acciones ficticas y acciones adyecticias. Fórmulas, cit., pp. 179-180, 203 y 228.

${ }^{19}$ S. SOLAZZI, "Sulla capacità del $<<$ filius familias $>>$ di stare in giudizio", en Scritti di Diritto romano, I, cit., pp. 1; GARCÍA GARRIDO, Ivs Vxorivm. El régimen patrimonial de la mujer casada en el derecho romano, cit., pp. 6. n. 8; MURGA, Derecho romano clásico, II. El proceso, cit., pp. 72; PUGLIESE, Il processo civile romano, cit., pp. 282; PERIÑÁN GÓMEZ, Antecedentes y consecuencias del SC. Macedoniano, cit., pp. 105.

${ }^{20}$ D. XLIV, VII, 39 (Gaius libro III. ad Edictum provinciale). SOLAZZI, "Sulla capacità del $<<$ filius familias $>>$ di stare in giudizio", cit., $1 \mathrm{ss}$, con abundantes fuentes al respecto; PUGLIESE, Il 
El problema, a juicio de Pugliese, era saber qué eficacia tendría la condena dado que, "exceptuada la hipótesis de que el filius familias dispusiese de un peculio castrense, no parece imaginable una ejecución patrimonial de la condena mediante missio in bona y bonorum venditio. Por otro parte, la ejecución personal (ductio por parte del acreedor y rescate mediante trabajo) se encontraba con el obstáculo de la $<<$ perdurante patria potestà $>>121$.

En el mismo sentido se manifiesta Murga para quien, si bien no se excluía desde el punto de vista teórico el ejercicio de la actio iudicati contra el filius familias, la dificultad en el plano práctico era hacer efectiva la sentencia condenatoria dado que, al carecer de patrimonio propio, no podría responder económicamente de tal forma que la condena no sería ejercitable hasta la extinción de la patria potestad ${ }^{22}$. Por otro lado, como afirma Periñán Gómez, aunque la jurisprudencia admitió que si disponía de un peculio castrense, pudiera con el mismo responder de sus deudas y cumplir sus condenas, tal y como nos indica Ulpiano: usque ad quantitatem castrensis peculii, cum filii familias in castrensi peculio vice patrum familiarum fungantur ${ }^{23}$, de acuerdo con un pasaje de Paulo su sujeción a responsabilidad era independiente de que tuviera o no peculio: Ideoaque si pater filio peculium ademisset, nihilo minus cresitores cum filio agere posunnt ${ }^{24}$.

En distinta situación procesal se encontraba, a juicio de Solazzi, la filia familias, cuya legitimidad pasiva se podía en línea de máxima excluir ante su incapacidad de asumir obligaciones civiles, de acuerdo con lo expresado por Gayo: Sed servus quidem et qui in mancipio est et filia familias et quae in manu est non solum ipsi, cuius iuri subiecti subiectaeve sunt, obligari non possunt, sed ne alii quidem ulli ${ }^{25}$. Una única excepción encuentra Pugliese a este principio sobre un pasaje de Paulo, en el que el

processo civile romano, cit., pp. 282-283; MURGA, Derecho romano clásico, II. El proceso, cit., pp. 72 n. 62; M. MARRONE, "La rivendica contro i <<filiifamilias", en Studi in onore di Giuseppe Grosso, VI, Torino, 1968, pp. 178 ss; PERIÑÁN GÓMEZ, Antecedentes y consecuencias del SC. Macedoniano, cit., pp. 111.

${ }_{21}$ PUGLIESE, Il processo civile romano, cit., pp. 286; VALIÑO; "Las actiones adiecticiae qualitatis $>>$ y sus relaciones básicas en Derecho romano", cit., pp. 340; KASER, Derecho romano privado, cit., pp. 221; PERIÑÁN GÓMEZ, Antecedentes y consecuencias del SC. Macedoniano, cit., pp. 112, afirma que no hay constancia explícita en las fuentes de que el filius pudiera sufrir las consecuencias de la ejecución personal. Cfr. SOLAZZI, "Sulla capacità del $<<$ filius familias $>>$ di stare in giudizio", cit., $3 \mathrm{ss}$, para quien existen más razones a favor que en contra de que el hijo pudiera sufrir una condena in personam.

${ }^{22}$ MURGA, Derecho romano clásico, II. El proceso, cit., pp. 72-73; PERIÑÁN GÓMEZ, Antecedentes y consecuencias del SC. Macedoniano, cit., pp. 112-113, precisa además que, extinguida la patria potestas, el beneficium competentiae limitaba, no obstante, la responsabilidad del filius hasta el límite del valor neto de lo heredado o le excluía de la misma si no heredaba de su padre por haber sido desheredado o emancipado o si se hubiera abstenido de la herencia. Al respecto, vid también, VALIÑO, "Las <<actiones adiecticiae qualitatis $>>$ y sus relacions básicas en Derecho romano", cit., pp. 390. Cfr. D. XIV, V, 5 pr.

${ }^{23}$ D. XIV, VI, 2 (Ulpianus libro LXIV. ad Edictum). PERIÑÁN GÓMEZ, Antecedentes y consecuencias del SC.Macedoniano, cit., pp. 112; SOLAZZI, "Sulla capacità del $<<$ filius familias $>>$ di stare in giudizio", cit., pp. 2 ss.

${ }^{24}$ D. XV, I, 45 (Paulus libro LXI. ad Edictum). PERIÑÁN GÓMEZ, Antecedentes y cosnecuencias del SC.Macedoniano, cit., pp. 112; SOLAZZI "Sulla capacità del $<<$ filius familias $>>$ di stare in giudizio", cit., pp. 2 ss.

${ }^{25}$ GAYO, Institutae, III, 104. SOLAZZI, "Sulla capacità del $<<$ filius familias $>>$ di stare in giudizio", cit., 1 y 33 ss; PUGLIESE, Il processo civile romano, cit., pp. 292; GARCÍA GARRIDO, Ivs Vxorivm. El régimen patrimonial de la mujer casada en derecho romano, cit., pp. 7. 
jurisconsulto considerar posible dirigirse contra la uxor hija de familia mediante la actio rerum amotarum: Si filia familias res amovert, Mela Fulcinius aiunt de peculio dandam actionem, quia displicuint eam furti obligari: vel in ipsam ob res amotas dari actionem ${ }^{26}$.

\section{2. Independencia domiciliaria del filius familias.}

La posibilidad de que el filius familia fuese titular de un domicilio independiente en época clásica, dado el progresivo incremento de su autonomía como consecuencia del debilitamiento de la familia patriarcal, es aceptada por la doctrina en el sentido ya apuntado por Savigny para quien, si bien los hijos legítimos desde el momento de su nacimiento tenían el domicilio del padre, podían más tarde abandonarlo y elegir otro libremente ${ }^{27}$.

A juicio de Ayiter, tres textos de Ulpiano son clarificadores en este sentido. En su comentario a Sabino, el jurisconsulto afirma que está determinado que los hijos de familia pueden tener domicilio: Placet, etiam filios familia domicilium habere posse $e^{28}$. En su comentario al Edicto precisa que el hijo de familia tiene su domicilio no donde lo tuvo el padre sino donde él mismo lo constituyó: non utique ubi pater habuit, sed ubicunque ipse demicilium constituit ${ }^{29}$. Y en sus Opiniones cierra la cuestión afirmando

${ }^{26}$ D. XXV, II, 3, 4. PUGLIESE, Il processo civile romano, cit., pp. 293; GARCÍA GARRIDO, Ivs Vxorivm. El régimen patrimonial de la mujer casada en derecho romano, cit., pp. 10: "Creemos, no obstante, que la tesis sobre la incapacidad general debe ser aceptada con algunas reservas, ya que no ofrece dudas el hecho de que en derecho justinianeo la hija se considera capaz de obligarse igual que el hijo y no nos parece que, en principio, deba ser excluído el que ya en el tardo derecho clásico comenzaran a introducirse excepciones a la originaria incapacidad". Cfr. SOLAZZI "Sulla capacità del $<<$ filius familias $>>$ di stare in giudizio", cit., pp. 21 ss y 33 ss.

${ }^{27}$ DE SAVIGNY, Sistema de derecho romano actual, cit., pp. 156. En el mismo sentido, A. GASPARD, Recherches sur l'incolat, le droit de bourgeoisie et le domicile, Paris, 1851, pp. 15-16; H. CHAVANES, Du Domicile, Paris, 1963, pp. 66-67; A. ANCELLE, Du Domicile, Paris, 1875, pp. 56; F. ROUSSEL, Du Domicile, en dorit romain; de la Formation des conventions, en droit international privé, Paris, 1878, pp. 29-30; K. AYITER, "Einige Bemerkungen zum Domicilium des Filius Familias im römischen Recht", en Studi in onore di Emilio Betti, II, Milano, 1962, pp. 76 ss; PLESCIA, "Conflict of laws in the roman Empire", cit., pp. 51-52.

${ }^{28}$ D. L, I, 3 ( Ulpianus libro XXV. ad Sabinum). AYITER, "Einige Bemerkungen zum Domicilium des Filius Familias im römischen Recht", cit., pp. 76 ss. En el mismo sentido, SAVIGNY, Sistema de Derecho romano actual, cit., pp. 156 n. (t); GASPARD, Recherches sur l'incolat, le droit de bourgeoisie et le domicile, cit., pp. 15; CHAVANES, Du Domicile, cit., pp. 67; ANCELLE, Du Domicile, cit., pp. 56; ROUSSEL, Du Domicile, en droit romain; de la Formation des conventions, en droit international privé, cit., pp. 30; V. TEDESCHI, "Contributo allo studio del domicilio in Diritto romano", en Rivista Italiana per la Scienze Giuridiche, 1932, pp. 233; idem, Del Domicilio, Padove, 1936, pp. 8; A. BURDESE, su voz <<domicilio (Diritto romano) $>>$, en Enciclopedia del Diritto, XIII, Milano, 1958, pp. 838; SALGADO, "Contribución al estudio del <<domicilium $>>$ en el Derecho romano", cit., pp. 504; PLESCIA, "Conflict of laws in the roman Empire", cit., pp. 52; Y. THOMAS, $<<$ Origine $>>$ et $<<$ Commune Patrie $>>$. Etude de Droit public romain (89 av. J.-C. - 212 ap. J.-C.), Paris, 1996, pp. 46 n. 59; A. GUZMÁN BRITO, Derecho privado romano, Tomo I, Sintesis histórica del Derecho romano. Las acciones y el proceso. El derecho de las personas y de la familia. El derecho de las cosas y de su dominio, posesión, uso y goce. El derecho de las obligaciones, Barcelona, Buenos Aires, México D.F., Santiago de Chile, 1997, pp. 287.

${ }^{29}$ D. L, I, 4 (Ulpianus libro XXXIX. ad Edictum). AYITER, "Einige Bemerkungen zum Domicilium des Filius Familias in römischen Recht", cit., pp. 76 ss. En el mismo sentido, SAVIGNY, Sistema de derecho romano actual, cit., pp. 156 n. (t); GASPARD, Recherches sur l'incolat, le droit de bourgeoisie 
que el hijo sigue el origo, no el domicilio, de su padre: Filius civitatem, ex qua pater eius naturalem originem ducit, non domicilium sequitur ${ }^{30}$.

Así mismo, esta autonomía domicilia se constata en un pasaje de Papiniado recogido por Salgado, en virtud del cual, si el padre cambiaba de domicilio, el hijo habitante de otra ciudad no quedaba sujeto a las cargas civiles en la ciudad en la que padre se hubiese domiciliado dado que también en cuanto a la persona del padre es temporal la razón del domicilio: Patris domicilium filium aliorum incolam civilibus muneribus alienae civitatis non adstringit, quum in patris quoque persona domicilii tratio temporaria sit $^{31}$.

Sin embargo esta independencia domiciliaria, en opinión de Thomas, podría darse incluso antes de que el filius poseyera una autonomía patrimonial dado que, de acuerdo con la evolución de la noción de domus, efectuada a caballo entre finales del siglo II a. C. y principios del siglo I a. C., ésta se había desvinculado de sus ataduras sociales más concretas para pasar a designar el lugar de residencia permanente con independencia de toda modalidad de propiedad o habitación, esto es, el domicilio ${ }^{32}$.

En este sentido Fayer recoge algunas fuentes literarias en las que se observa el declive de la convivencia entre padres e hijos en el último siglo del período republicano, es decir, en un momento coetáneo o ligeramente posterior al surgimiento de las primeras

et le domicile, cit., pp. 15; CHAVANES, Du Domicile, cit., pp. 67; ANCELLE, Du Domicile, cit., pp. 56; ROUSSEL, Du Domicile, en droit romain; de la Formation des conventions, en droit international privé, cit., pp. 30; TEDESCHI, "Contributo allo studio del domicilio in Diritto romano", cit., pp. 233; idem, Del Domicilio, cit., pp. 8; BURDESE, su voz $<<$ domicilio (Diritto romano) >>, cit., pp. 838; SALGADO, "Contribución al estudio del $<<$ domicilium $>>$ en el Derecho romano", cit., pp. 504; PLESCIA, "Conflict of laws in the roman Empire", cit., pp. 52; THOMAS, $<<$ Origine $>>$ et $<<$ Commune Patrie $>>$. Étude de Droit public romain (89 av. J.-C. - 212 ap. J.-C.), cit., pp. 46 n. 59; GUZMÁN BRITO, Derecho privado romano, I, cit., pp. 287.

${ }^{30}$ D. L, I, 6, § 1 (Ulpianus libro II. Opinionum). AYITER, "Einige Bemerkungen zum Domicilium des Filius Familias im römischen Recht", cit., pp. 76 ss; SAVIGNY, Sistema de derecho romano actual, cit., pp. 156 n. (t); GASPARD, Recherches sur l'incolat, le droit de bourgeoisie et le domicile, cit., pp. 15; CHAVAnES, Du Domicile, cit., pp. 67; ANCELLE, Du Domicile, cit., pp. 56; ROUSSEL, Du Domicile, en droit romain; de la Formation des conventions, en droit international privé, cit., pp. 30; TEDESCHI, "Contributo allo studio del domicilio in Diritto romano" cit., pp. 233; idem, Del Domicilio, cit., pp. 8; VISCONTI, "Note premilinari sull'<<origo $>>$ nelle fonti romane", cit., pp. 104; BURDESE, su voz $<<$ domicilio (Diritto romano) $>>$, cit., pp. 838; SALGADO, "Contribución al estudio del $<<$ domicilium $>>$ en el Derecho romano", cit., pp. 504; PLESCIA, "Conflict of laws in the roman Empire", cit., pp. 52; THOMAS, $<<$ Origine $>>$ et $<<$ Commune Patrie $>>$. Étude de Droit public romain (89 av. J.-C. - 212 ap. J.-C.), cit., pp. 46 n. 59; GUZMÁN BRITO, Derecho privado romano, I, cit., pp. 287.

${ }^{31}$ D. L, I, 17, § 11 (Papinianus libro I. Responsorum). SALGADO, "Contribución al estudio del $<<$ domicilium $>>$ en el derecho romano", cit., pp. 504; SAVIGNY, Sistema de derecho romano actual, cit., pp. 156 n. (t); GASPARD, Recherches sur l'incolat, le droit de bourgeoisie et le domicile, cit., pp. 15; CHAVAnES, Du Domicile, cit., pp. 67; ANCELlE, Du Domicile, cit., pp. 56; TEDESCHI, "Contributo allo studio del domicilio in Diritto romano", cit., pp. 233; idem, Del Domicilio, cit., pp. 8; VISCONTI, "Note preliminari sul $<<$ domicilium $>>$ nelle fonti romane", cit., pp. 436; BURDESE, su voz $<<$ domicilio (Diritto romano) $>>$, cit., pp. 838; AYITER, "Einige Bermerkungen zum Domilium des Filius Familias im römischen Recht", cit., pp. 76 ss; PLESCIA, "Conflict of laws in the roman Empire", cit., pp. 52; THOMAS, $<<$ Origine $>>$ et $<<$ Commune Patrie $>>$. Étude de Droit public romain (89 av. J.-C. - 212 ap. J.-C.), cit., pp. 46 n. 59.

32 THOMAS, $<<$ Origine $>>$ et $<<$ Commune Patrie $>>$. Étude de Droit public romain (89 av. J.-C. 212 ap. J.-C.), cit., pp. 34 ss. 
actiones adiecticiae qualitatis. Entre ellas, dignas de mención son dos pasajes de Cicerón.

En el primero nos indica que los hijos adultos, los consobrini y sobrini, los primos de primer y segundo grado, habitaban en casas diversas cuando una sola casa no podía contenerlos a todos: "Nam cum sit hoc natura commune animantium, ut habeant lubidinem procreandi, prima societas in ipso coniugio est, proxima in liberis, deinde una domus, communia omnia; id autem est principium urbis et quasi seminarium rei publicae. Sequutur fratum coniunctiones, post consobrinorum sobrinorumque, qui cum una domo iam capi non possint, in alias domos tamquam in colonis exeunt ${ }^{\prime 33}$.

En el segundo, como indica Fayer, el propio Cicerón defiende a Celio de los reproches esgrimidos por los jueces como consecuencia de haber abandonado la casa del padre para ir a vivir en una casa sobre el Palatino, afirmando que tales reproches están fuera de lugar, dados los tiempos y la edad de Celio, más aún si se tiene en cuenta que había abandonado la casa paterna no sólo con el permiso sino por consejo del padre, cuya casa estaba alejada del Foro: "Reprehendistis a patre quod semigravit: quod quidem iam in hac aetate minime reprehendendum est... non modo permittente patre, sed etiam suadente ab eo semigravit, et, cum domus patris a foro longe abesset, quo facilius et nostras domus obire et ipse a suis coli posset, conduxit in Palatino non magno domum ${ }^{\prime 34}$.

\section{EL FORO TERRITORIAL COMPETENTE EN LAS ACTIONES ADIECTICIAE QUALITATIS FRENTE A LOS NEGOCIOS CELEBRADOS POR EL FILIUS FAMILIAS: UNA PROPUESTA DE SOLUCIÓN.}

Constatada la posibilidad de que el filius familias fuese parte pasiva a partir del proceso formulario y de que pudiera ser titular de un domicilio independiente, nos proponemos resolver la cuestión relativa a cual era el foro territorial ante el que debían interpornerse las acciones adyecticias en el supuesto de que pater et filius tuviesen un domicilio distinto: ante el magistrado de la circunscripción territorial del domicilio del pater familias o ante el de la circunscripción territorial del domicilio del hijo ${ }^{35}$.

33 CICERÓN, Philosophica. De officiis, I, 54. FAYER, La familia romana, cit., pp. 71; B. RAWSON, "The Roman Family", en B. RAWSON, (Ed.), The Famiy in ancient Rome. New perspectives, London, 1992, pp. 14, quien sobre este pasaje afirma que, si bien algunos hijos de familia adultos, casados e incluso con descendencia, continuaban viviendo con sus progenitores, esta convivencia parece haber sido rara en este período.

${ }^{34}$ CICERÓN, Orariones. Pro. Caelio, XVIII. FAYER, La familia romana, ci., pp. 72; RAWSON, "The Roman family", cit.,pp. 17.

${ }^{35}$ Nos obstante, no debemos olvidar que este problema de jurisdicción podría ser resuelto en Roma si el actor se acogía al foro de origen y no al domicilio (D. L, XVI, 190; C.I. III, XIII, 2), en la medida en que, con excepción de algunas civitas privilegiadas, el filius familias seguía el origo de su pater. Al respecto, D. L, I, $1 \S 2$ (Ulpianus libro II. ad Edictum); L, I, 1 pr.; C.I. X, XXXVIII(XXXIX), 3; SAVIGNY, Sistema de derecho romano actual, cit., pp. 146; A. VISCONTI, "Note preliminari sull'<<origo >> nelle fonti imperiali romane", en Studi Carlo Calisse, I, Milano, 1939, pp. 95 y 104-105; D'ORS, Epigrafía jurídica de la España romana, cit., pp. 151-153; THOMAS, $<<$ Origine $>>$ et $<<$ Commune Patrie $>>$. Étude de Droit public romain (89 av. J.-C. - 212 ap. J.-C.), cit., pp. 51 ss.

Además no debemos olvidar que el demandado tuvo a su disposición foros especiales, algunos de tarde aparición, para asegurar mejor su reclamación: el lugar de cumplimiento de la obligación contractual (D. V, I, 19 § 3; D. XLII, V, 1 y 3); el forum rei sitiae (C.I. III, XIX, 3); o el forum commissi 
Una postura favorable al foro territorial del filius familias puede deducirse, $a$ priori, de la opinión de Solazzi en virtud de la cual, en el supuesto de que el hijo tuviera un domicilio distinto, la utilidad de dirigir el juicio contra él sería patente, por ejemplo, en lo que concierne a la prueba y por las mismas razones, entiende que "pudo parecer a veces ventajoso dirigir el juicio de cognición contra el filius, y frente al padre solo el de ejecución" ${ }^{\prime 36}$. No obstante, el autor acaba reconociendo que no es posible excluir otro modo de proceder.

A nuestro juicio, el problema de la competencia territorial reside en saber qué obligatio era realmente la sancionada a través de estas acciones y, por ende, cómo debemos interpretar el hecho de que el filius figurase en la intentio.

En relación con el primer punto, Guarino consideraba que con estas acciones se sancionó "la posibilidad de que los sometidos a potestas obligasen a sus patresfamilias, haciéndoles responsables de las consecuencias onerosas de algunos actos lícitos" siempre y cuando, hubiesen consentido o autorizado el negocio o se hubieran beneficiado $^{37}$. A la vista de esta opinión, compartida por muchos autores, parece desprenderse que estas acciones sancionaban una obligatio del pater y no un obligatio propia del filius, si bien el mismo había sido el actor del negocio generador de la obligación con el tercero $^{38}$. La misma conclusión se deduce de un pasaje de Gayo en virtud del cual el jurisconsulto fundamenta la producción de tales efectos en la persona del pater en el hecho de que el que hace el negocio en estas condiciones lo hace por fiarse más del padre o del dueño que del hijo o del esclavo: et recte, quia qui ita negotium gerit, magis patris dominive quam filii servive fidem sequitur ${ }^{39}$.

delecti (D. V. I, $24 \S 1$; IX, IV, 43). Al respecto, entre otros, SAVIGNY, Sistema de Derecho romano acutal, cit., pp. 162 ss; GASPARD, Recherches sur l'incolat, le droit de bourgeoisie et le domicile, cit., pp. 11 ss; CHAVANES, Du Domicile, cit., pp. 85 ss; ANCELLE, Du Domicile, cit., pp. 68 ss; ROUSSEL, Du Domicile, en droit romain; de la Formation des conventions, en droit international privé, cit., pp. 39 ss; PUGLIESE, Il processo civile romano, II. Il processo formulare, cit., pp. 153 ss; BRUGUIÈRE, "Le domicilie dans les droits antiques", cit., pp. 214; PLESCIA, "Conflict of laws in the roman Empire", cit., pp. 48.

${ }^{36}$ SOLAZZI, "Sulla capacità del $<<$ filius familias $>>$ di stare in giudizio", cit., pp. 3.

${ }^{37}$ GUARINO, su voz $<<$ actiones adiecticiae qualitatis $>>$ cit., pp. 271.

38 VOLTERRA, Instituciones de Derecho privado romano, cit., pp. 83 y 171, indica que estas acciones se interponen contra el dominus o pater; PROVERA, Lezioni sul processo civile giustinianeo, cit., pp. 263, para quien con las acciones adyecticas "si ammise che figli e schiavi potessero, pur entro certi limiti ed a certe condizioni, obbligare il propio pater o dominus"; D'ORS, Elementos de Derecho privado romano, cit., pp. 54-55, para quien el jefe doméstico autorizante queda directamente obligado en virtud de es estas acciones; HERNANZ PILAR, El ivssvm en las relaciones potestativas, cit., pp. 130 , con relación a la actio quod iussu nos indica que el fundamento de la obligación del pater familias frente al tercero descansa en esa voluntas domini, denominada iussum: "de donde se infiere que el efecto sui generis de este consentimiento declarado estriba en hacerse responsable el propio iubens inmediatamente, con su patrimonio, de los negocios celebrados por un alieni iuris suyo, cuya actuación repercute en el esfera jurídica de aquél"; GARCÍA GARRIDO, Derecho privado romano, cit., pp. 300, indica que eran acciones con les que se podía demandar al padre por las deudas y negocios realizados por los sometido; MARTÍN MINGUIJÓN, Acciones ficticias y acciones adyecticias. Fórmulas, cit., pp. 152 y 154: "Estas acciones tienen su fundamento en la realización de un acto jurídico, con consecuencias en el patrimonio de un cabeza de familia por una persona distinta de él... mediante el recurso a la transposición de sujetos en la fórmula, se responde por los actos celebrados en nombre del pater familias por persona distinta de él", obviando el principio civil por el cual una persona no podía quedar obligada por un contrato o negocio realizado por otro.

${ }^{39}$ GAYO, Institutae, IV, 70-71. 
No obstante, como señala Miceli, las fuentes jurídicas eliminan toda duda al respecto puesto que en ellas claramente se pone de manifiesto que la obligatio sancionada por estas acciones es propiamente la del pater o la del sujeto a favor del cual se producen los efectos del negocio concluido y no la obligación del filius ${ }^{40}$. En este sentido, la autora recoge una serie reponsa que se refieren a todas las actiones adiecticiae qualitatis, no quedando ninguna excluida ${ }^{41}$. Así, por ejemplo:

- Respecto a la actio exercitoria:

D. XIV, I, $1 \S 4$ (Ulpianus liber XXIII. ad Edictum): Cuius autem condicionis sit magister, nihil interest, utrum liber an servus, et utrum exercitoris an alienus: sed nec cuius aetatis sit, intererit, SIBI IMPUTATURO QUI PRAEPOSUIT ${ }^{42}$.

- Respecto a la actio institoria:

D. XIV, III, $5 \S 11$ ( Ulpianus liber XXVIII. Ad Edictum): Non tamen omne, quod cum institore geritur, OBLIGAT EUM QUI PRAEPOSUIT, sed ita, si eius rei gratia, cui praepositus fuerit, contractum est, id est dumtaxat ad id quod eum praeposuit ${ }^{43}$.

- Respecto a la actio de peculio:

D. XV, I, $3 \S 9$ (Ulpianus liber XXIX. ad Edictum): Sed si filius fideiussor vel quasi interventor acceptus sit, an de peculio PATREM OBLIGAT, quaeritur. Et est vera Sabini et Cassii sententia existimantium semper OBLIGARI PATREM DE PECULIO et distare in hoc a servo ${ }^{44}$.

- Resoecto a la actio quod iussu:

D. XV, IV, 1 pr.(Ulpianus liber XXIX. ad Edictum): Merito ex iussu DOMINI IN SOLIDUM ADVERSUS EUM IUDICIUM DATUR, nam quodammodo cum eo contrahitur qui iubet ${ }^{45}$.

- Respecto a la actio de in rem verso:

D. XV, III, $3 \S 5$ (Ulpianus liber XIX. ad Edictum): Idem Labe ait, si servus mutuatus nummos a me alii eos crediderit, de in rem verso dominum teneri, quod nomen ei adquisitum est: quam sententiam Pomponius ita probat, si non peculiare nomen fecit, sed dominicae rationis. Ex qua causa hactenus ERIT DOMINUS OBLIGATUS, ut, si non putat sibi expedire nomen debitoris habere, cedat creditori actionibus procuratoremque eum faciat ${ }^{46}$.

\footnotetext{
${ }^{40}$ MICELI, Sulla struttura formulare delle 'Actiones adiecticae qualitatis', cit., pp. 31-32, a su juicio desde que el filius familias asume capacidad para obligarse se evidencia más claramente que con estas acciones se hace valer una responsabilidad personal del pater.

${ }^{41}$ MICELLI, Sulla struttra formulare delle 'Actiones adiecticiae qualitatis', cit., pp. 185 ss, donde constata que algunos de ellos no están exentos de alteraciones pero que las mismas no afectan a la determinación de la obligación paterna o del señor del negocio como la perseguida a través de estas acciones.

${ }^{42}$ Vid., así mismo, D. XIV, I, $1 \S 3$.

${ }^{43}$ Vid., igualmene, D. XIV, III, 1.

${ }^{44}$ Vid, así mismo, D. XV, I, $3 \S 3$; XV, I, 3 §; XV, I, 5 § 1.

${ }^{45}$ Vid, igualmente, GAYO, Institutae, IV, 70; D. XVI, I, 25 pr., entre otros.

${ }^{46}$ Vid., respecto a la actio tributoria, D. XIV, IV, $1 \S 2$.
} 
Por otro lado que la obligación perseguida a través de estas acciones era la del pater se confirma, a su vez, en el hecho señalado por Valiño sobre un pasaje de Paulo, de que su ejercicio no excluía que el tercero pudiera reclamar directamente contra el hijo con quien realmente había contratado: Item si servus meus navem exercebit, et cum magistro eius contraxero, nihil obstabit, quominus adversus magistrum experiar actione, quae mihi vel iure civili, vel honorario competit; nam et cuivis alii non obstat hoc Edictum, quominus cum magistro agere possit; hoc enim Edicto non transfertur actio, sed adiicitur ${ }^{47}$.

A la vista de las consideraciones expuestas, nos parece más acertado apuntar como foro territorial competente para el conocimiento de las acciones adyecticias aquél determinado por el domicilio del pater familias, sin que nuestra propuesta se confronte con el segundo punto de nuestro análisis, esto es, con el hecho de que el filius familia figurara en la intentio de la fórmula de estas acciones adyecticas dado que la misma era debida, de acuerdo con la opinión de Valiño, a que estas acciones no podían concebirse aisladamente en la medida en que su función era complementaria de aquélla otra principal que podía interponerse directamente contra el hijo, sobre la que se moldeaban y cuyos carácteres reflejaban en su fórmula respectiva ${ }^{48}$.

${ }^{47}$ D. XIV, I, $5 \S 1$ (Paulus libro XXIX. ad Edictum). Esta acción directa contra el filius sí se interpondría ante el magistrado de su domicilio aunque si no tenía un peculio castrense carecería de eficacia práctica. VALIÑO, "Las <<actionis adieticiae qualitatis $>>$ y sus relaciones básicas en Derecho romano", cit., pp. 340-341, para quien las acciones adyecticias contra el padre se añadían a la acción existente contra el hijo, de tal forma que el padre no respondía en lugar sino conjuntamente con el hijo; FERNÁNDEZ DE BUJÁN, El $<<$ Filiusfamilias $>>$ independiente en Roma y en el Derecho español, cit., pp. 26 considera que el padre se obligaba solidariamente; KASER, Derecho privado romano, cit., pp. 221, se refiere a una responsabilidad adicional del pater; PROVERA, Lezioni sul processo civile giustinianeo, cit., pp. 259 y 279; FERNÁNDEZ BARREIRO-PARICIO, Fundamentos de Derecho patrimonial romano, cit., pp. 178 para quienes con estas acciones se hacía valer una responsabilidad del padre o señor que se añadía a la del hijo o el esclavo; F. BETANCOURT, Derecho romano clásico, Sevilla, 1995, pp. 436 ss; D'ORS, Derecho privado romano, cit., pp. 303, prefieren hablar de acciones "agregadas" a la acción que procedía contra el alieni iuris o servus e interpretan el término in solidum, como responsabilidad por el total pero precisan que en el caso de la actio de peculio y de la actio de in rem verso, su responsabilidad quedaría limitada a la cuantía del peculio o del beneficio obtenido; GARCÍA GARRIDO, Derecho privado romano, cit., pp. 300, considera que el padre no respondía en lugar del hijo o esclavo sino conjuntamente con él y se obligaba solidariamente (in solidum). Por su parte MARTÍN MINGUIJÓN, Acciones ficticias y acciones adyecticias. Fórmulas, cit., pp. 153-154, considera que estas acciones socn accesorias y por el total y estima que las diferentes posturas tienen su fundamento en una distinta interpretación del "hoc enim edicto non transfertur actio, des adicitur" en el sentido de acumulación de acciones, en lugar del carácter accesorio, como del término "in solidum" en el sentido de obligación solidaria, en lugar de responsabilidad por el total pero, en todo caso, afirma que resulta contradictorio considerar la responsabilidad del padre como solidaria y defender, al mismo tiempo, que la acción de éste se acumule a la del hijo. Cfr. MICELI, Sulla struttura formulare delle 'Actiones adiecticia qualitatis', cit., pp. 208 ss, para quien la responsabilidad del hijo, esclavo o prepuesto ha sido indebidamente generalizada.

${ }^{48}$ VALIÑO, "Las <<actiones adiecticiae qualitatis $>>$ y sus relaciones básicas en Derecho romano", cit., pp. 340-341, afirma que esta acción principal aparece omitida en el Digesto, tal vez por razones de brevedad; CANNATA, Profilo istituzionale del processo privato romano, cit., pp. 131, considera que en relaidad las denominadas acciones adyecticas son más bien estructuras formularias aplicables a varias acciones; PROVERA, Lezioni sul processo civile giustinianeo, cit., pp. 265 ss, reconoce también que estas acciones no eran autónomas; WACKE, "Alle origini della rappresentanza diretta: Le azioni adiettizie", cit., pp. 239-240, considera que estas aciones consistían en una modificación de la acción básica a través de la cual se extendía la legitimación pasica al padre o dominus negotii. 
Más concretamente, como expone Martín Minguijón, con estas acciones sólo se podía exigir la responsabilidad del pater, cuando su filius hubiera efectuado el negocio en los límites de la praepositio, del iussum, del peculio o del beneficio patrimonial causado al pater y se dieran, en consecuencia, los presupuestos jurídicos que originaban su obligación ${ }^{49}$. De ahí que, convenimos con la autora, en su fórmula se debía mencionar tanto al hijo como el sujeto que había efectuado con el tercero el negocio como los presupuestos necesarios para hacer surgir la obligación del padre e imputarle la condena. La fórmula de estas acciones quedaría, por tanto, configurada del modo siguiente ${ }^{50}$ :

- En la intentio figuraría el nombre del filius como la persona con la que se ha contratado y el contrato que se ha efectuado;

- En la demostratio respectiva se harían constar los presupuestos necesarios para hacer posible la obligatio del pater: que el filius es un magister navis o un institor nombrado por el pater, es decir, la existencia de la praepositio en la actio exercitoria y en la actio institoria; la existencia del peculio junto con la relación de potestad, en la actio de peculio y en la actio de in rem verso; y esa relación de postestad junto con el iussum, en la actio quod iussu ${ }^{51}$; $\mathrm{y}$

${ }^{49}$ MARTÍN MINGUIJÓN, Acciones ficticias y acciones adyecticias. Fórmulas, cit., pp. 153-154 y 183. La limitación del ejercicio de las acciones adyecticias a los supuestos en que concurrieran estos requisitos ha sido reiterada en la doctrina. Al respecto, entre otros, por DE MARTINO, "Studii sull' $<<$ actio exercitoria $>>$ ", cit., pp. 7 ss; idem, "Anconra sull'<<actio exercitoria $>>$ ",cit., pp. 275 ss; VALIÑO, "Las $<<$ actiones adiecticae qualitatis $>>$ y sus relaciones básicas en Derecho romano", cit., pp. 340-34; LONGO, "<<Actio exercitoria $>>$ - <<actio institoria $>>$ - <<actio quasi institoria $>>$ ", cit., pp. 583; MURGA, Derecho romano clásico, II. El proceso, cit., pp. 73-74; PROVERA, Lezioni sul processo civile giustinianeo, cit., pp. 263 ss; D'ORS, Elementos de Derecho privado romano, cit., pp. 54-55; idem, Derecho privado romano, cit., pp. 303-304; FERNÁNDEZ BARREIO-PARICIO, Fundamentos de Derecho patrimonial romano, cit., pp. 178-179; PERIÑÁN GÓMEZ, Antecedentes y consecuencias del SC. Macedoniano, cit., pp. 114.

${ }^{50}$ MARTÍN MINGUIJÓN, Acciones ficticias y acciones adyecticias. Fórmulas, cit., pp. 184-184 (actio exercitoria, D. XIV, I, 1 pr; D. XIV, I, 1 § 7 y 12), 192-193 (actio institoria, D. XIV, III, 3; D. XIV, III, 5 § 11), 209 (actio quod iussu, Gayo, Institutae, IV, 70; D. XIV, V, 1), 220-221 (actio de peculio y actio de in rem verso, D. XV, III, 16, entre otros). Sobre la fómula de estas acciones, vid., también, CANNATA, Profilo istituzionale del processo privato romano, cit., pp. 132 ss; BETANCOURT, Derecho romano clásico, cit., pp. 436 ss; D. MANTOVANI, Le formule del processo privato romano. Per la didattica delle Istituzioni di diritto romano, Padova, 1999, pp. 79 ss. Cfr. MICELI, Struttura formulare delle 'Actiones adiecticiae qualitatis', cit., pp. 35, 37 ss, 89 ss y 354 ss, que considera que en la intentio de la fórmula debería indicarse la obligación del pater familias eliminado de este modo la transposición de personas. No obstante, compartimos la opinión de PROVERA, Lezioni sul processo civile giustinianeo, cit., pp. 265 y 285, de que una fórmula que enunciase en la intentio la obligación del pater habría aparecido seguramente concedida, en el origen de estas acciones, en abierta violación de los principios del ius civile. Sólo con posterioridad, una vez que se reconoció la representación directa, vendría a menos la distinción operada entre intentio e condemnatio hasta que en el sistema de la cognitio, estas acciones aparecerían como unas acciones normales que correspondían al acreedor frente al pater o dominus negotii. Sobre esta evolución, WACKE, "Alle origini della rappresentanza diretta: Le azioni adiettizie", cit., pp. 258 ss.

${ }^{51}$ La definición en la demostatio de los presupuestos de la acción, ha sido apuntada, entre otros por VALIÑO, "Las <<actiones adiecticiae qualitatis $>>$ y sus relaciones básicas en Derecho romano", cit., pp. 383-384, 407 y 436, entre otras; LONGO, "<<Actio exercitoria $>>-<<$ actio institoria $>>-<<$ actio quasi institoria $>>$ ", cit., pp. 582; HERNANZ PILAR, El ivssvm en las relaciones potestativas, cit., pp. 88 n. 5. 
- En la condemnatio figuraría el nombre del pater ${ }^{52}$.

La determinación de la jurisdicción competente a través del domicilio del pater es, de acuerdo con esta reconstrucción de la fórmula, perfectamente conciliable con el hecho de que en la intentio figurase el nombre del filius, dado que en ella se le indicaba como autor del negocio jurídico y en la demostratio quedaba patente que dicho negocio había sido efectuado con los presupuestos necesarios para obligar al pater frente al tercero lo que permitía, en consecuencia, exigir su responsabilidad en la condemnatio ${ }^{53}$.

Finalmente, como señala Wacke, no obstante su naturaleza jurídica, no se trataba de acciones meramente "subsidiarias" dado que teniendo en cuenta que el hijo, el esclavo o el prespuesto carecían a menudo de patrimonio, desde el punto de vista del del interés económico del tercero contratante, la responsabilidad del dominus negotii o del titular de la potestad adquiría un papel de primer orden, en la medida en que el tercero calculará los riesgos del negocio en función de la fiabilidad de aquél y de la posibilidad de satisfacer los posibles créditos frente al mismo ${ }^{54}$.

\section{CONCLUSIÓN.}

1. Las acciones adyecticias eran acciones con transposición de personas de tal forma que en la intentio figuraba el nombre del filius y en la condenmatio el nombre del pater.

2. Ello planteaba el problema de determinar cual era el foro territorial competente para su conocimiento en el supuesto en que el filius, reconocida su legitimación procesal pasiva, fuese titular de un domicilio independiente distinto del domicilio paterno.

3. Teniendo en cuenta que la obligatio que se pretende sancionar con estas acciones es la del pater y que su función es complementaria de otra principal que el tercero podía interponer directamente contra el hijo, consideramos que el foro territorial competente sería el determinado por el domicilio del pater familias.

${ }^{52}$ Así mismo, a juicio de PROVERA, Lezioni sul processo civile giustinianeo, cit., pp. 270, en el caso de la actio de peculio y en la actio de in rem verso, la condemnatio sería cum taxatione, esto es, se especificaría que la reponsabilidad del pater alcanzaba hasta el límite del peculio o del beneficio obtenido.

${ }^{53}$ Es por ello que, a juicio de WACKE, "Alle origine della rappresenanza diretta: le azioni adiettizie", cit., pp. 258 ss, estas acciones fueron el mecanismo que abrió la puerta a la admisión de la inicialmente no reconcida representación directa. En este sentido, entre otros, VOLTERRA, Instituciones de Derecho Privado romano, cit., pp. 173, apunta que ya el el siglo III d. C., Papiniano (D. XIV, III, 19 pr.) afirmaba que aquél que hubiera realizado negocios con el procurador o mandatario de un tercero podía exigir reponsabilidad al tercero o mandante mediante la actio quasi institoria y que en el derecho justinianeo se admitió la actio de rem in verso contra el representado por el provecho obtenido con el negocio realizado por el representante; GUARINO, su voz <<actiones adiecticiae qualitatis $>>$, cit., pp. 272; VALIÑO, "Las $<<$ actiones adiecticiae qualitatis $>>$ y sus relaciones básicas en derecho romano", cit., pp.364-365; MURGA, Derecho romano clásico II. El proceso, cit., pp. 96-97; PROVERA, Lezioni sul processo civile giustinianeo, cit., pp. 260; D'ORS, Derecho privado romano, cit., pp. 533-534; MARTÍN MINGUIJÓN, Acciones ficticias y acciones adyecticias. Fórmulas, cit., pp. $182,198,203$ y 209, entre otras.

${ }^{54}$ WACKE, "Alle origini della rappresentaza diretta: Le azioni adiettizie", cit., pp. 240. 
4. Esta competencia territorial es perfectamente compatible con la figuración en la intentio del nombre del hijo como autor del negocio generador de la obligatio, dado que en la demostratio quedaría patente que el mismo había actuado con los presupuestos necesarios para obligar al pater frente al tercero. 